\title{
7. Theory Building in Action: Structured-case with action interventions
}

\author{
Gerlinde Koeglreiter \\ University of Melbourne \\ Ross Smith \\ RMIT University \\ Luba Torlina \\ Deakin University
}

\section{Abstract}

In this chapter an enhancement of the structured-case approach, including action research-style interventions within structured-case cycles, is discussed. An exemplar of this approach is provided through a knowledge management study. The major benefits of this approach include the flexibility of the resulting research process to include cycles both with and without action interventions, its capacity to support a study involving many research cycles conducted over an extended time scale (amounting, in the study described, to several years) and, most importantly, the capacity of the approach to make visible the theory building that takes place.

\section{Introduction}

This chapter discusses recent developments in the application of the structuredcase (SC) approach of Carroll and Swatman (Carroll, 2000; Carroll and Swatman, 2000). Specifically, a theory-building approach using action research (AR) interventions as part of a larger program of research undertaken in an SC mode is presented. 
Structured-case and AR share characteristics that facilitate their combined use, including the iterative conduct of research cycles that are structured into phases of planning, data collection, analysis and reflection. Further, both methodologies support research conducted within the interpretive research paradigm.

For the study described in this chapter, a methodology was required that would support a complex research agenda, including investigation of phenomena drawing on rich field data and extensive literature from distinct disciplines, sensitive stakeholder interactions and a study of dynamics of these interactions. These factors might be relevant to many projects in the multifaceted information systems (IS) discipline, thus making the proposed combination of research methods beneficial to many research projects facing similar research settings. Further, the proposed combined methodology has been found effective for a project that seeks to address both theoretical requirements and practical goals, including responsiveness to research participants' needs, action interventions and theory building over an extended period (amounting, in the present study, to several years).

In this particular context, pure AR might pose challenges to theory building. Action research requires an intervention to serve the dual imperative of inducing change to improve an organisational problem situation and building theory (McKay and Marshall, 2001; McKay and Marshall, 2007). In practice, however, to accommodate organisational needs, multiple intervention cycles over a short period might require intense periods of research (Schultze, 2000), often leaving the theory-building part behind to occur at a later stage.

The research settings discussed above create the need for a research methodology that combines two forms of research activity in an iterative process. This chapter argues that a structured approach, as facilitated by SC, with reduced pressure on inducing change as mandated by $\mathrm{AR}$, but with the advantages of the rich information obtained in participant observation and evaluation of organisational impact, allows the researcher to spend more time on reflection, increasing the depth of theory being built. The focus on the theoretical foundation facilitates careful consideration of subsequent interventions, so aligning the practical response with a coherent theoretical framework. This approach might therefore find wider applicability to IS research projects that pursue systems-based problem solving both for theory building and for testing.

Structured-case has been promoted as a means of supporting theory building as part of case study research (Carroll, 2000; Carroll and Swatman, 2000). While SC follows a cyclical approach, as does AR, it focuses on theory building based on analysis of the extant literature and reflection on the present and previous cycles. 
Structured-case might be extended to include interventions involving participant/participatory observation and evaluation of organisational impact to obtain rich data and develop, deepen and test theory in a cyclical approach. In the present chapter, a study is outlined that applies such an approach. This approach was found particularly suitable for a project with a complex agenda, conducted over a long period and seeking to achieve both change management and rich theory building.

Specifically, this chapter reports methodological findings from a $\mathrm{PhD}$ project that combined SC and AR interventions to develop a multifaceted framework of organisational knowledge management (KM). The chapter is structured as follows: the background section sets the research context of the study and describes the problem situation in terms of the requirements that were placed upon the selection of an appropriate methodology. Subsequent sections provide an introduction to AR and structured-case. Then, the findings are reported, bringing together the elements of these two methodologies in a coherent research program and describing the process of analysis and theory building that was conducted over four cycles of research. The concluding section provides a brief discussion of the perceived advantages of the process employed and summarises the chapter's contribution to research practice.

\section{Background}

The research project described in this chapter sought to build a multifaceted framework for organisational KM involving a community of practice (CoP), as the core group to be studied, and other entities of the wider organisation in which the CoP existed, as well as interdependencies between the parties.

The program of research involved investigation of the role of a CoP in organisational KM and was conceived as a 'bottom-up' study. The CoP was a group of academics teaching systems implementation subjects in the School of Information Systems at an Australian university. More specifically, the research sought to understand the role a CoP might play in collaborative $\mathrm{KM}$ and knowledge strategy development.

Extant research has acknowledged that CoPs might be viewed as a bottom-up approach to KM, and that such approaches need to be coordinated with topdown KM efforts (Wenger et al., 2002). The research aimed to provide insights into how these two approaches might be implemented as part of a coherent, comprehensive KM strategy. A comprehensive KM strategy would be one that integrates top-down KM (strategic and mandated by management) and bottomup KM (work practice-oriented and owned by a CoP at lower hierarchical levels in the organisation). This approach considers a range of factors related to 
knowledge work, performed both by CoPs and by management, and entails a strong social aspect, involving knowledge flows between a CoP and the wider organisation.

Consistent with the aim and nature of the project, the research agenda included exploration of complex and interlacing considerations of the social aspects that facilitate a CoP, the nature of knowledge work and knowledge work support, both technical and non-technical. The research also included the organisational elements of management and leadership style, strategic alignment and disciplinary and organisational boundary conflicts. Importantly, a bottom-up approach was taken to investigate $\mathrm{KM}$, focusing primarily on inputs from staff at lower hierarchical levels of the organisation.

Initially, the aim was predominantly practice oriented since the researcher saw the need, and opportunities, to improve the situation of the community of practice. This kind of situation can be considered as ideal for an AR project aiming at significant change. In the early stages of the project, however, the need for adjustments to the research process was recognised. Factors contributing to the changes in the research project involved organisational changes impacting on the priorities of the group under study, and an opportunity for conducting observations over a longer period to gain a deeper understanding of the CoP knowledge work. As a result, the opportunity was taken to develop the project in the direction of a more complex research agenda, shifting the primary goal of introducing organisational change, as practiced in AR, to generating knowledge (Gaventa and Cornwall, 2001). The goal had thus shifted to theory building as the primary purpose of the study, introducing only limited organisational change.

Action research interventions focus primarily on problem solving, with a secondary focus on the generation of knowledge (Gaventa and Cornwall, 2001). Structured-case, as the overarching methodological framework, involves cycles of interpretive case study, with a focus on theory development drawing upon field data. Structured-case does not intend directly to induce change and address the organisational issues faced by the CoP, but rather seeks to develop deeper understanding of the systemic aspects of knowledge work conducted by the group. Both methods were supposed to inform each other within a single research design, enriching a series of conceptual frameworks. A further requirement of the adopted methodology was that it should facilitate the extraction of theory from masses of field data and broad research themes (Carroll and Swatman, 2000). 
The requirements described above can be accommodated within the SC approach, which originally drew upon the AR process, and which allows selection of any research processes, tools and techniques at each cycle of activity for theory building (Carroll and Swatman, 2000).

This chapter acknowledges similarities to the action case method (Vidgen and Braa, 1997) that combines soft case study and AR as a means of addressing the need to balance intervention and interpretation. Vidgen and Braa (1997) recommend action case for projects of short to medium duration, small-scale interventions and a narrow research focus. Action case was evaluated as an alternative method in our situation, but was found unsuited to the planned long-term research project, with its flexible and hence complex agenda and its strong focus on a transparent presentation of theory building throughout the project.

In response to these imperatives, an approach was adopted that included AR interventions within a broader program of structured-case. In the following sections the elements of SC and AR are discussed in terms of their contribution to the overarching research program.

\section{Structured-Case}

Structured-case (SC) is 'a methodological framework that assists IS researchers to undertake and assess theory building research within the interpretive paradigm, and explains its value in achieving convincing explanations that are strongly linked to both the research themes and data collected in the field' (Carroll and Swatman, 2000, p. 235). Structured-case supports the use of different tools and processes to build and validate theory.

The SC methodology builds on the case study methodology and employs structural elements of AR (Carroll, 2000). Its basis is the case, in the sense of what is being studied. 'Structured' refers to the formal process model, and consists of three elements. The first element is a conceptual framework representing the researcher's aims. Structured-case suggests that the research subject matter (Carroll, 2000) can be based on either an assumption that concepts will emerge purely from large amounts of data collected, with little predefined structure, as advocated in grounded theory (Glaser, 1992; Strauss and Corbin, 1998), or on preconceived notions and a conceptual structure that can underpin the research, based on available, but possibly scarce, resources (Orlikowski and Baroudi, 1991). Second, a predefined research cycle guides data collection, analysis and interpretation. Finally, literature-based scrutiny compares and contrasts the outcomes of the research process with a broad range of literature to support or challenge the theory built (Carroll and Swatman, 2000). 
In SC, a multi-staged process helps the researcher to organise data collection and analysis (Carroll, 2000), providing a predefined structure for the conduct of research and development of theory. The SC research cycle includes stages of planning, data collection, analysis and reflection (see Figure 7.1).

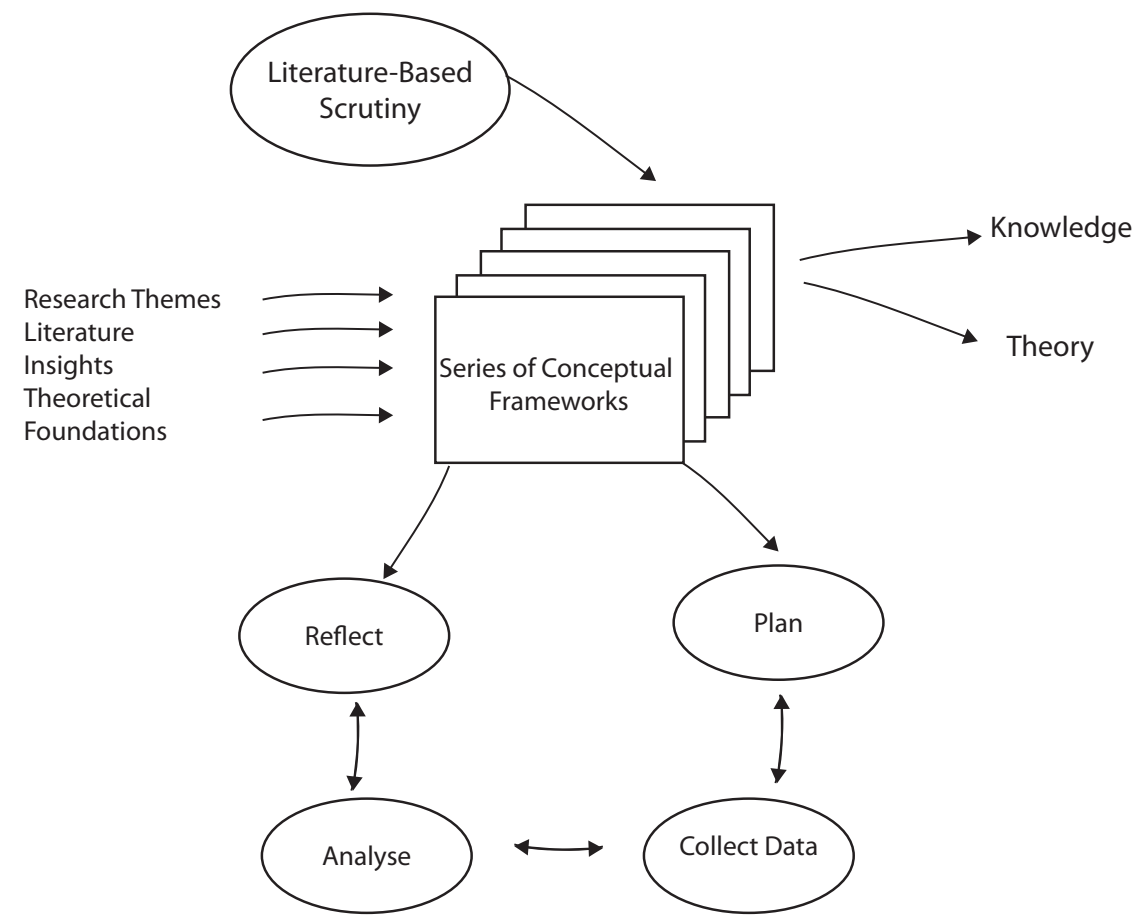

Figure 7.1 The Structured-Case Research Cycle

Source: Carroll and Swatman (2000).

The development of the conceptual framework is conducted through a series of research cycles. Each of the cycles informs and extends the previous cycle, refining the conceptual framework to a point of saturation, which is determined by the researcher. The reflective stages as part of the cyclical approach also support a process of abstraction. Structured-case supports theory building within the interpretative paradigm and assists in generating a significant level of abstraction. 


\section{Action Research}

Action research (AR) has been defined as 'a cognitive process that depends on social interaction between the observers and those in their surroundings' (Baskerville and Wood-Harper, 1998, p. 92).

What distinguishes AR from other methodologies is that it involves practical problem solving that has theoretical relevance (Mumford, 2001). Action research is conducted in cycles of interventions, where outcomes examined in one cycle are the input to the next cycle, with the overall intent to change the situation for the better. The researcher is heavily involved in the organisational life of the research subjects and might even be one of their colleagues.

Essentially, AR consists of two major stages (see Figure 7.2): a diagnostic stage where a social situation is collaboratively analysed; and a therapeutic stage involving collaborative change experiments where changes are introduced and the effects studied (Blum, 1955). These two stages are implemented in a cyclical process, linking theory and practice (Baskerville and Wood-Harper, 1996).

Baskerville and Wood-Harper (1998) identify four characteristics by which the various AR methods can be classified: process model, structure, typical researcher involvement and primary goals. The AR process model might be reflective (theory-in-use versus espoused theory), linear (single sequence of activities) or iterative (repeated cycles of activity until a satisfactory outcome is achieved). The structure of AR can be rigorous, following predefined rules, or fluid, where activities are defined loosely. The typical researcher involvement can be facilitative (researcher takes an advisory role), expert (the researcher's task is to solve the problem) or collaborative (researcher and participants are equal).

If applied in organisational development, AR aims at improving the human organisation, including the development of the social conditions of the organisation. Action research, as used in systems design, seeks to create or modify organisational systems. If undertaken with the educational goal of creating scientific knowledge, AR attempts to produce a generalisable understanding that practitioners can use in different settings or that other researchers build upon in subsequent studies.

To ensure that both the problem-solving and the research interests are addressed, a parallel dual-cycle process that also addresses the research interest has to be followed (McKay and Marshall, 2001). Eden and Huxham (1995) suggest that this should take place via a comprehensive AR design, which involves a continuous writing process to inform theory exploration and implicit pre-understanding. 


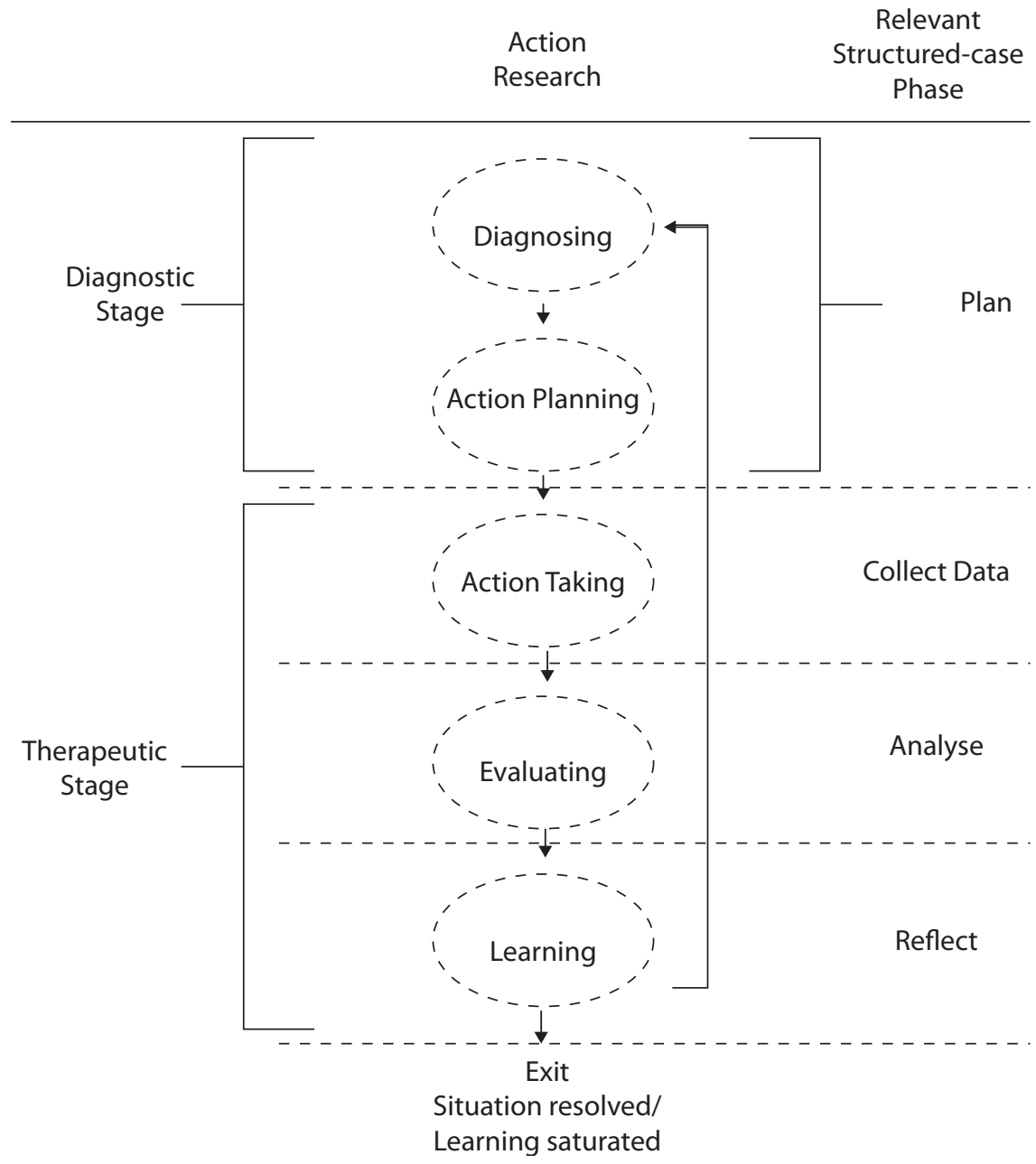

Figure 7.2 The Action Research Cycle

Source: Adapted from Baskerville and Wood-Harper (1996, 1998); and Blum (1955).

\section{Structured-Case with Action Interventions}

As already noted, the SC approach was adapted in the present study to include AR-style interventions within three of four research cycles. As such, practiceoriented change took place, but within a SC framework that facilitated the emergence of theoretical insights. One research cycle did not include action in the form of an intervention with the aim to introduce change, but took a more conventional case study approach, to investigate the theoretical linkage of the CoP's practice with the formal organisation. Reporting the research undertaken within a SC framework accommodates this. Figure 7.3 depicts the modified research cycle including action interventions, encompassing a synthesis of the process and essence of SC (see Figure 7.1) and AR (see Figure 7.2). 


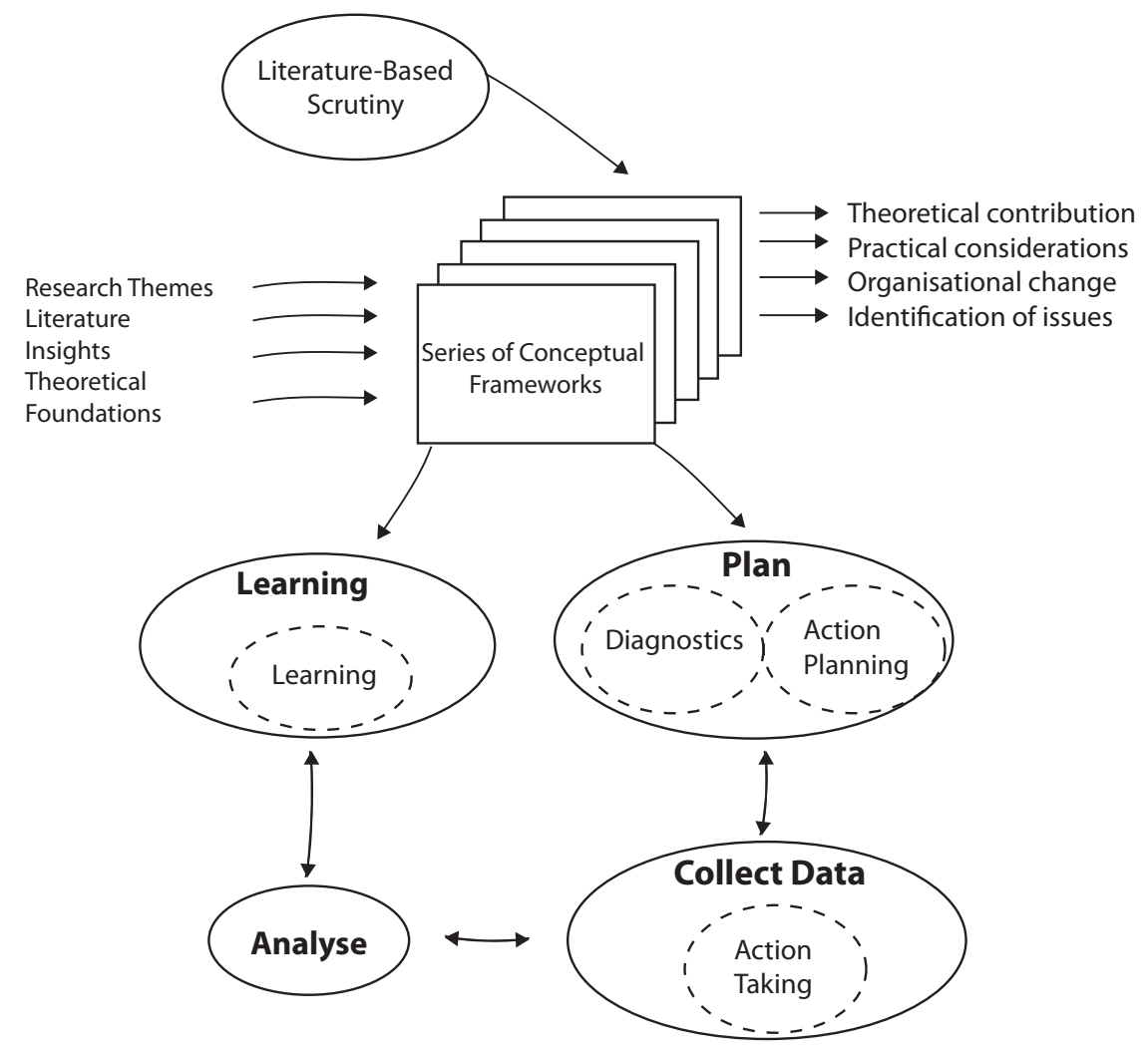

Figure 7.3 The Structured-Case Research Approach Including Elements from AR

Source: Adapted from Baskerville (1999); and Carroll (2000).

The following sections describe each stage in the research approach, depicted in Figure 7.3, in the context of SC, action interventions and their application in the present study.

\section{Plan}

Both SC and AR cycles involve a planning phase. In SC the planning stage includes formulation of the research themes extracted through theory examination and data collection planning, including considerations of data collection requirements and data analysis techniques (Yin, 1994), as well as selection of the research site and participants.

Action research starts with a diagnostic phase involving considerations of practical requirements, such as identifying primary problems as the underlying causes of the organisation's desire to change (Baskerville, 1999). In AR the 
planning phase is primarily concerned with action or intervention planning to relieve or improve primary problems identified in the diagnostic phase. Action is planned through guidance of the theoretical framework indicating the desired future state and changes that would achieve such a state (Baskerville, 1999).

In the present study, the AR diagnostic stage was integrated into the SC planning phase to address the requirements and issues encountered by the research subjects, setting a practical objective for each research cycle. Then, literature considered relevant for the diagnosed problem situation was analysed and used as a basis for developing theory-oriented interview questions. Data collection planning primarily involved the design of interview schedules. For cycles with action interventions, workshop agendas were agreed with participants.

Because not all cycles of research need to include action interventions, the integration of the diagnostic and action planning stages is optional and presents a sub-structure to the overall SC cycle structure. While logically intertwined, the practical and theoretical components of the planning phase are, therefore, clearly separated in the presentation of action and theory input.

\section{Collecting Data}

In $\mathrm{AR}$, data collection is undertaken in an 'action taking' phase primarily involving notes from participants or participatory observation (Jorgensen, 1989; Kemmis and McTaggert, 2000). This 'data collection in action' approach has exposed AR to criticism as simply a consultation exercise masquerading as research and hence as lacking rigour (Baskerville and Wood-Harper, 1996).

In SC, data collection is guided by the plan devised in the planning stage. By adhering to the SC cycle structure, the focus on theory is continually revisited throughout the stages of the cycle. Data collection and analysis may be overlapping, as immediate analysis of field notes containing the researcher's interpretations might open up new areas of exploration (Carroll, 2000). The data collection process, therefore, involves adjustments responding to opportunities, unexpected outcomes and emergent themes (Carroll, 2000).

Where AR-style interventions were conducted, the action-taking phase involved implementation of the planned action in the form of workshops. Further, interview schedules were designed to contain questions that reflected participants' impressions of the intervention sessions, relating those with concepts identified in the theory examination stage. While all workshop participants were asked the same questions in the same order, the questions were designed to allow the interviewee to describe specific situations as examples. Adjustments in the data collection phase involved addition and refinement of interview questions between interviews. 
The collection of data in two formats (workshops and interviews) enabled a separation of the practical and theoretical focuses. Workshops were conducted in a semi-structured manner with sufficient flexibility to address the diagnosed practical problem. Further, this fluid style of action taking is conducive to generating emergent themes through participants raising issues that might not be directly related to the problem addressed in that cycle, but are nevertheless of interest to the researcher in subsequent research cycles or to enrich the understanding of complex situations when presenting an account. The interview format enforced a stronger theory orientation and provided participants with an opportunity for deep reflection, both on the practical situation and in relation to theoretical concepts that were integrated into the interview questions.

\section{Analysis}

While the analysis phase may involve the same techniques in both AR and SC, the strong theoretical focus of SC demands a stronger guidance of analysis by literature.

Analysis involves an iterative process of reading and rereading the vast amounts of raw data typical of qualitative research, developing a deep understanding and relating the data to the conceptual framework (Carroll, 2000). Techniques involve coding related to research themes from the conceptual framework and the identification of new concepts based on themes emerging in the course of analysis.

In the present study, data were analysed in iterations. First came the coding of data based on concepts identified in the literature and the evolving framework. Second was the identification of new concepts through a process of writing up interview summaries and extraction of concepts that the research identified as new. Third, a microanalysis was undertaken to examine the underlying meaning of the text and to extract more concepts. Fourth, concepts were interlinked into higher level categories.

While both SC and AR involve a data analysis or evaluation stage, SC advocates this stage as a central element of the research, acknowledging that analysis is undertaken in a nonlinear fashion and may occur throughout the various stages of one or multiple SC cycles (Carroll 2000). For example, in the present study the researchers returned to transcripts of earlier cycles to reanalyse data in the context of the current cycle, or to identify concepts and issues that spanned cycles, so informing the emerging theory on a higher level. This assisted in the development of a coherent framework that addressed issues from a diverse set of angles. 


\section{Reflection}

Both SC and AR include a reflection stage in their research cycle structure. In SC, deliberate reflection and critical analysis of any interpretations are formal stages of the research process, derived from AR (Carroll, 2000). In $\mathrm{AR}$, reflection involves an evaluation step to assess practical and theoretical outcomes and to critically consider the influences of the intervention on the outcomes (Baskerville, 1999). Reflection in AR also includes the formulation of learning, where new knowledge gained during the intervention flows into the organisation, or alternatively triggers a new cycle if the outcomes are considered unsuccessful or new issues are identified (Baskerville, 1999).

In integrating action interventions in SC cycles, it is essential that the learning stage from AR is also integrated. In the present study, the learning stage assisted in identifying new issues that were addressed in subsequent research cycles, so creating a 'practical' double loop, in parallel with the theory-focused SC loop, which feeds directly into the diagnostic stage of the planning phase in a new cycle of research.

The reflection phase focuses on theory building based on the understanding of theory as a system of interconnected ideas that condenses and organises knowledge(Neuman, 2006). Theorising involves relating the findings to outcomes of previous research cycles, revisiting literature (Carroll, 2000) or returning to informants to confirm tentative interpretations (Trauth, 1997). The reflection stage entails iteration between data (from current and previous cycles), the tentative findings and the inputs to the conceptual framework and recording of the rationale for changing the conceptual framework (Carroll, 2000). Outcomes of reflection include challenge and support of the conceptual framework, or revision and update, based on the findings of the current research cycle. The result is an extended conceptual framework incorporating new concepts and/or refined existing concepts.

In summary, the enhancement of SC with action interventions strengthens the evolving conceptual framework through the parallel presentation of the theoretical contribution and immediate testing of the framework through practical considerations, organisational change and potential identification of issues. 


\section{An Application of Structured-Case with Action Interventions}

As discussed above, the research approach taken in the present study sought to link the SC concepts of Carroll and Swatman (2000) (see Figure 7.1) with the AR notion of diagnostic and therapeutic stages (Figure 7.2). Specifically, the research adopted the SC method with action interventions and was conducted in four cycles (see Table 7.1) to investigate the CoP as the 'case' and its interaction with the wider organisation in a KM context. Each SC cycle typically consists of stages of planning, data collection, analysis and reflection. Some of these phases were broken down further to address elements of AR, including diagnostics in the planning phase, action taking in the data collection phase and learning as part of the reflection phase. As required for SC, the findings were captured in an evolving conceptual framework $(\mathrm{CF} 1-\mathrm{CF} 4)$, visually representing the theory being built.

Action interventions were undertaken as a series of group workshops (three workshops, two hours each), involving a CoP of five lecturers in IS and selected members of the wider organisation. These interventions were followed up in reflective interviews (semi-structured and lasting one hour). The series of interventions evolved, following the needs of the group as extracted in the analysis phase at the end of each research cycle. Theory building followed the set theme of bottom-up KM influences observed in the interaction of the CoP with the wider organisation.

The combination of SC with action interventions provided an opportunity to facilitate change and to undertake the research and theory building. This mixed method removed some of the rigidity associated with single methodologies and hence allowed for flexibility. For example, in the present study one cycle did not involve any action intervention (CF2), and a follow-up investigation of change was undertaken in only one of the four research cycles (CF3). As such, the four cycles would not have formally met the requirements of an AR project.

As an example, to assist readers in understanding Table 7.1, a brief description of research cycle one is provided in what follows. Research cycle one involved an action intervention that aimed at declaring a group as a community of practice. The planning phase started with a diagnosis that the group required a focused environment to exchange information on their work-related projects and identify common interests, and that individuals understand the concept of a CoP and identify themselves as CoP members. To underpin this practical goal, relevant theory on CoP characteristics was examined. Finally, in action planning, a workshop was planned to address the practical goals and a follow-up interview schedule was designed to bring together reflections on the workshop 
in conjunction with the theory examined. The data collection phase involved action in the form of a workshop, where CoP members presented their work and engaged in conversations on each other's work. Data collection methods included workshop observations that were logged by the researcher and reflective interviews with individuals. Following transcription of the interviews, data were analysed based on the concepts identified in the theory embedded in the interview schedule as well as issues and themes emerging from the group discussion and individual reflection. In the reflection phase the initial diagnosis was revisited and it was concluded that the goal had been achieved.

As required in SC, components that represent and describe theoretical and emerging concepts were captured in the evolving conceptual framework (CF1), including identity of the CoP, perceptions of organisational management, the relationship between the CoP and management, and knowledge work. Learning from reflection on the practical outcomes of the cycle was identified in that the CoP maintains complex and in part problematic relationships with entities of the wider organisation. This was addressed and investigated further in a subsequent research cycle (cycle three).

\section{Conclusion}

The integration of SC and AR as applied in the reported study brought with it a number of benefits that might be useful for other IS research projects.

First, the SC/AR integrated approach serves the purpose of developing and testing a conceptual framework in an iterative process. The modified methodology suits the research agenda of theory building by looking at the organisational situation and the research participants through different lenses. From a practical perspective, action interventions aid improvement of the organisational situation.

Second, with action interventions being optional in the proposed approach, a research cycle that focuses on purely theoretical aspects can be included. This can be seen as different to a mixed-method approach since the structure of the presentation of the research process and the development of the conceptual framework remain consistent with the presentation of the other research cycles.

Third, the primary focus on supporting theory building reduces the expectation of achieving substantial organisational change inherent in the AR approach. This might be considered useful by those employing action interventions for the first time or for researchers who lack the organisational power or stakeholder support that is generally required to induce and evaluate significant change. 
7. Theory Building in Action: Structured-case with action interventions

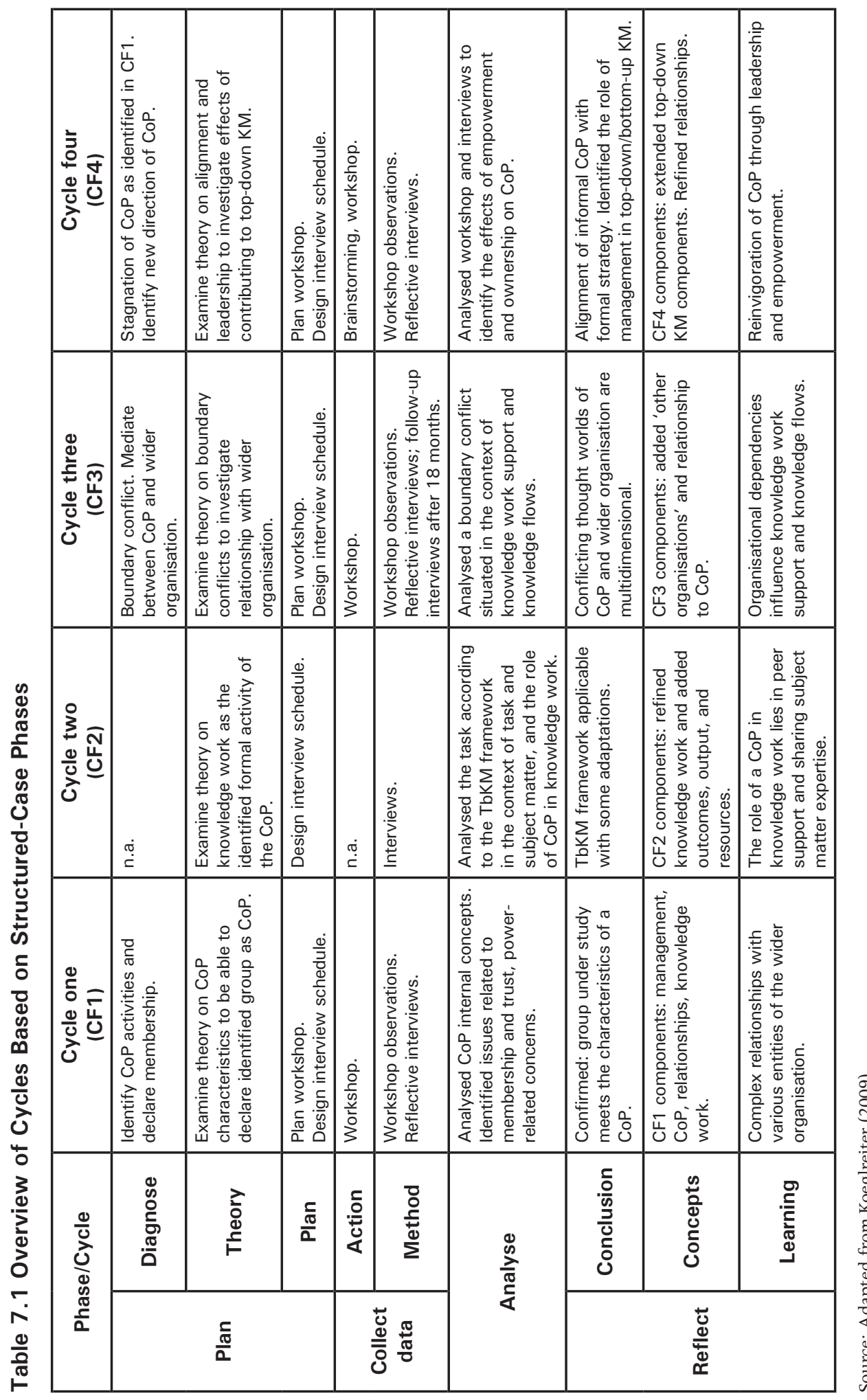


Fourth, if cycles are designed to be conducted independently of each other, more time can be taken to thoroughly examine the extant literature, combined with reflections on findings. This assists in gaining deeper theoretical insights over an extended period. This is difficult to achieve in AR projects that might require significant results to be achieved over a short period in order to establish organisational change momentum.

Fifth, the complexity associated with comprehensive conceptual frameworks requires that the researcher is able to adequately present the theory-building process as a coherent piece of work. Action research studies have been criticised for failing this requirement, due to their primary objective of solving an organisational problem. Structured-case with action interventions, by its highly structured nature, however, forces the action researcher to return to the relevant existing theory and clearly outline the contribution to the evolving theory throughout the data collection process.

Finally, the combination of SC and AR is supported by an extended set of research evaluation criteria (Klein and Myers, 1999; Koeglreiter 2009; Narayanaswamy and Grover, 2007).

In a project conducted as action research, each research cycle is expected to involve an intervention. For the study reported in this chapter this would have meant that significant theoretical findings extracted from an intervention-free cycle would not have been achieved. The combination of SC and AR gives the researcher flexibility to choose whether or not action is required to achieve the theoretical goal, but presents intervention-free cycles in the same format and as carrying equal significance to those cycles that include interventions.

Action research enhances SC, complementing the theoretical focus with a practical perspective. Interpretive studies based on interview data might be limited, as the researcher has to rely on the stories told by participants. Observations made in participant and participatory research-typical for $\mathrm{AR}$ - might assist the researcher to paint a richer picture of the organisational situation and prompt them to take into consideration subtleties that might be missed in interview situations.

Structured-case reminds the action researcher of the theoretical focus. At each research cycle relevant literature is consulted, which might draw on a variety of knowledge domains. In a pure SC approach, literature may be consulted only in the initial stages of the project, thus maintaining a narrow focus on the case throughout the process. In contrast, the changing nature of AR might require consultation of additional literature that is applicable to the problem situation of the current cycle, thus enhancing the case through taking a more systemic view. 
All of this might be considered useful by IS researchers engaging in longerterm projects to assist them with documenting the theory-building process in a practice-oriented setting.

In concluding, it is noted that future research embedding action interventions within SC cycles, conducted in research contexts other than knowledge management, would assist in establishing the wider applicability of the research approach that has been described here.

\section{References}

Baskerville, R. L. (1999). Investigating information systems with action research. Communications of the Association for Information Systems, 2(3), 1-32.

Baskerville, R. L., \& Wood-Harper, T. A. (1996). A critical perspective on action research as a method for information systems research. Journal of Information Technology, 11(3), 235-46.

Baskerville, R. L., \& Wood-Harper, T. A. (1998). Diversity in information systems action research methods. European Journal of Information Systems, $7(2), 90-107$.

Blum, F. (1955). Action research - a scientific approach? Philosophy of Science, $22(1), 1-7$.

Carroll, J. M. (2000). Understanding the early stages of the requirements engineering process in practice. Doctoral thesis, Swinburne University of Technology, Melbourne, Vic.

Carroll, J. M., \& Swatman, P. A. (2000). Structured-case: a methodological framework for building theory in information systems research. European Journal of Information Systems, 9(4), 235-42.

Eden, C., \& Huxham, C. (1995). Action research for the study of organizations. In S. Clegg, C. Hardy \& W. Nord (eds), Handbook of Organization Studies (pp. 526-42). London, UK: Sage Publications.

Gaventa, J., \& Cornwall, A. (2001). Power and knowledge. In P. Reason \& H. Bradbury (eds), The SAGE Handbook of Action Research: Participative inquiry and practice (pp. 172-89). Thousand Oaks, Calif.: Sage Publications.

Glaser, B. (1992). Basics of Grounded Theory Analysis: Emergence vs forcing. Mill Valley, Calif.: Sociology Press. 
Jorgensen, D. L. (1989). Participant Observation: A methodology for human studies. Thousand Oaks, Calif.: Sage Publications.

Kemmis, S., \& McTaggert, R. (2000). Participatory action research. In N. K. Denzin \& Y. S. Lincoln (eds), Handbook of Qualitative Research (pp. 567-605). [Second edn]. Thousand Oaks, Calif.: Sage Publications.

Klein, H. K., \& Myers, M. D. (1999). A set of principles for conducting and evaluating interpretive field studies in information systems. MIS Quarterly, 23(1), 67-93.

Koeglreiter, G. (2009). Community of practice and the wider organisation: a multifaceted KM framework. Doctoral thesis, Deakin University, Melbourne, Vic.

McKay, J., \& Marshall, P. (2001). The dual imperatives of action research. Information Technology \& People, 14(1), 46-59.

McKay, J., \& Marshall, P. (2007). Driven by two masters, serving both. In N. Kock (ed.), Information Systems Action Research (pp. 131-58). New York, NY: Springer.

Mumford, E. (2001). Action research: helping organizations to change. In E. M. Trauth (ed.), Qualitative Research in IS: Issues and trends (pp. 46-77). Hershey, Pa: Idea Group Publishing.

Narayanaswamy, R., \& Grover, V. (2007). A critical assessment of information systems action research. In N. Kock (ed.), Information Systems Action Research (pp. 327-53). New York, NY: Springer.

Neuman, W. L. (2006). Social Research Methods: Qualitative and quantitative approaches. Boston, Mass.: Allyn and Bacon.

Orlikowski, W. J., \& Baroudi, J. J. (1991). Studying information technology in organizations: research approaches and assumptions. Information Systems Research, 2(1), 1-28.

Schultze, U. (2000). A confessional account of an ethnography about knowledge work. MIS Quarterly, 24(1), 3-41.

Strauss, A., \& Corbin, J. (1998). Basics of Qualitative Research: Techniques and procedures for developing grounded theory. [Second edn]. London, UK: Sage Publications.

Trauth, E. M. (1997). Achieving the research goal with qualitative methods: lessons learned along the way. In A. S. Lee, J. Liebenau \& J. I. DeGross (eds), Information Systems and Qualitative Research (pp. 225-45). Philadelphia, Pa: Chapman \& Hall. 
Vidgen, R., \& Braa, K. (1997). Balancing interpretation and intervention in information system research: the action case approach. In A. S. Lee, J. Liebenau \& J. I. DeGross (eds), Information Systems and Qualitative Research (pp. 524-41). Philadelphia, Pa: Chapman \& Hall.

Wenger, E., McDermott, R., \& Snyder, W. M. (2002). Cultivating Communities of Practice - A guide to managing knowledge. Boston, Mass.: Harvard Business School Press.

Yin, R. K. (1994). Case Study Research: Design and methods. [Second edn]. Thousand Oaks, Calif.: Sage. 